\title{
Compatibility of the Support System Consisting of Yielding Elements and Shotcrete Lining in Highly Faulted Grounds
}

\author{
Tina Marolt Cebasek and Jakob Likar \\ Faculty of Natural Sciences and Engineering, University of Ljubljana, Ljubljana SI-1000, Slovenia
}

\begin{abstract}
The design procedure is made for a mine shaft where permanent underground facilities are interconnected. The highly faulted grounds were identified using empirical and semi-empirical theories. Furthermore, the behavior types are presented. This paper presents excavation and support methods in such ground conditions and the calculations results show that the installation of the yielding elements have an effect on support elements and prevent shotcrete damage during the curing stage. Different numerical analyses carried out showed that, with the yielding elements installed, the total displacements increase but the final axial force reduces, and therefore, the characteristic compressive strength of shotcrete is not exceeded. The calculation results of ground loads and displacements on the designed support system are presented with a 3D numerical geo-mechanical model adopted for highly faulted ground surrounding deeper complex underground structures.
\end{abstract}

Key words: Faulted ground, yielding elements, mine shaft, 3D numerical model, ground reaction curve.

\section{Introduction}

The challenges associated with the construction of deep underground facilities in highly faulted grounds are still often subject to scientific and expert analyses in various ground conditions. At increased primary stress conditions, the behavior of highly faulted grounds is sometimes unpredictable. From a construction viewpoint, highly faulted grounds are associated with significant risks in major underground facilities. Methods and computational analyses, which are available nowadays, enable better approximations, so that the design solution is more realistic and ultimately more cost-effective. Correct predictions of the behavior in faulted ground conditions play an important role in underground structure design. In such conditions, construction faces many problems in completing underground works. The faulted ground conditions are a consequence of changed stress

Corresponding author: Tina Marolt Cebasek, B.Sc., teaching assistant, research fields: geotechnology and mining engineering. E-mail: tina.marolt@ogr.ntf.uni-lj.si. conditions. Nevertheless, the same rock could behave as non-faulted at a low overburden and as highly faulted at a high overburden. As a result of low strength and high deformability, faulted grounds are overstressed at a low stress level. This means that if a tunnel with identical geometric characteristics is located in the rock with the same geotechnical properties, the potential squeezing problems due to faulted grounds could appear in the tunnel with higher overburden. Furthermore, the strength of the faulted ground formations is not constant and consequently faulted grounds become weaker when exposed to underground facilities. The paper offers a proper design and a technical solution for a complex underground construction which consists of a shaft and mine's permanent facilities in highly faulted grounds.

\section{A Review of Theories}

Most of the theories are based on practical experiences and documented historical cases, they could be mainly divided into empirical [1-4] and semi-empirical approaches [5, 6-9]. 
Identification and indication of faulted grounds, and potential tunnel squeezing problems are discussed by Jethwa et al. [9] who included the data on the degree of squeezing in relation to the ratio of uniaxial compressive strength and the rock mass unit weight to overburden height. Singh et al. [3] integrated the theory, which is based on rock mass quality $Q$ (Barton et al. [10]) and considers overburden height. Furthermore, Goel et al. [1] explained the theory based on the rock mass number $(N)$ and considered the overburden height $(H)$ and the tunnel diameter $(B)$. The design of the support measures together with advance rate definition assuring a safe face excavation could only be performed successfully by defining the proper stress conditions in faulted grounds.

\section{Computational Assessment of the Faulted Ground Condition Rate by Different Authors}

Core drilling investigation (Fig. 1) provides data (Table 1) for the computational assessment (Table 2). The highly faulted grounds were determined using Singh, Jethwa and Goel theory for a mine roadway with the diameter of $4.6 \mathrm{~m}$.

Defined rate of faulted grounds provides a reasonable and rational design of support measures under evaluation advance rate of the excavation face. This can be carried out by the multiplied heading method or the full-face excavation method. Both methods are considered conventional excavation methods.

Where, $H$ is the overburden height, $Q$ is the rock mass quality, $N$ is the rock mass number and $B$ is the tunnel diameter.

It is established that all three theories present a similar solution $[11,12]$. And these findings are very important when designing a shaft.

\section{Geo-Metrical Data on the Analyzed Shaft and Underground Connection Facilities}

The basic geo-metrical design of the shaft (Fig. 2) was done by the Velenje Coal Mine design team, which defined the free inner diameter $\left(D_{s}\right)$ as $6.00 \mathrm{~m}$. The inner lining, from the reinforced cast concrete, needs to have a minimum thickness $\left(d_{s}\right)$ equal to $30 \mathrm{~cm}$. The thickness of the primary lining $(d)$ varies from $20 \mathrm{~cm}$ to $40 \mathrm{~cm}$, as it depends on the results of the geostatic calculations. Moreover, the total size of estimated construction tolerances $\left(T_{c t}\right) 10 \mathrm{~cm}$ and the deformation tolerances $\left(T_{d t}\right)$ from $10 \mathrm{~cm}$ to $20 \mathrm{~cm}$, were included in the shaft excavation geometry. Based on this input data, the excavation shaft diameter $\left(D_{e}\right)$ is projected to be between $7.40 \mathrm{~m}$ to $8.00 \mathrm{~m}$. The geometry of mine objects, which functions as a connection to the main shaft, is characterized by further operational demands. The basic inner cross section is $4.20 \mathrm{~m}$ and the excavation diameter is adequately extended from 5.00 $\mathrm{m}$ to $5.20 \mathrm{~m}$, considering both construction and deformation tolerances.

\section{A Short Description of the Engineering Geology Parameters in the Area of the New Shaft}

From the ground surface to the depth of approximately $80 \mathrm{~m}$, the layers of Plio-Quaternary age were found where an alteration of sand with thin layers of sandy clay, clayey sand, sandy silt is presented. According to the investigation $\log$, aquifers are presented at a depth of approximately $94 \mathrm{~m}$. The inclination of aquifer ground layers towards the shaft excavation area and low permeability of interlayers can cause water accumulation that can inflow into the excavation during the shaft sinking. Weak ground layers, which are sources of major tectonic damages at several locations, are seen in form of tectonic mechanical disruption of grounds with significantly decreased shear strength. Layers of weak ground decline at an angle of $7^{\circ}$ and contain intersected dense systems of cracks, fracture surfaces and joints. Forty-nine metres deeper, the primary stress exceeds the compressive strength of the ground samples for each reference depth. Therefore, below this depth, there is a high probability that a plastic zone will form around 
Table 1 Geological conditions.

\begin{tabular}{|c|c|c|c|c|c|}
\hline Ground type & \multicolumn{5}{|l|}{ GT-7 } \\
\hline Depth (m) & \multicolumn{5}{|l|}{$494-499$} \\
\hline Lithology & \multicolumn{5}{|l|}{ Marly silt } \\
\hline $\begin{array}{l}\text { Rock mass } \\
\text { characteristics }\end{array}$ & \multicolumn{5}{|c|}{$\begin{array}{l}\text { Tectonically disturbed, merely silt with slightly shale texture and individual pockets filled with clayey } \\
\text { component }\end{array}$} \\
\hline $\begin{array}{l}\text { Chemical } \\
\text { characteristics }\end{array}$ & \multicolumn{5}{|c|}{$\begin{array}{l}\text { Rock mass of } 15 \% \text { clayey fraction (illite and montmorillonite), the relatively high content of a quartz and } \\
\text { carbonates, the presence of the organic carbon and sulfur in the form of pyrite }\end{array}$} \\
\hline $\begin{array}{l}\text { RQD (rock quality } \\
\text { designation) }\end{array}$ & \multicolumn{5}{|c|}{$60 \%-70 \%$} \\
\hline $\begin{array}{l}\text { GSI (geological } \\
\text { strength index) }\end{array}$ & \multicolumn{5}{|l|}{$30-35$} \\
\hline \multicolumn{6}{|c|}{ Discontinuities } \\
\hline Stratification & \multicolumn{5}{|c|}{ Subhorizontal stratification, dip $7^{\circ}$} \\
\hline \multirow{6}{*}{ Cracks } & \multicolumn{5}{|l|}{ Joint set number Two joint sets plus random } \\
\hline & \multicolumn{5}{|c|}{ Orientation $\quad$ One system: sub-vertical and sub-horizontal according to the borehole axis } \\
\hline & \multicolumn{5}{|c|}{ Density $\quad 200-600 \mathrm{~mm}$} \\
\hline & \multicolumn{5}{|c|}{ Fill Cracks are filled with calcite and clayey material } \\
\hline & \multicolumn{5}{|c|}{ Inflow A possible inflow of water along the crack and tear zones } \\
\hline & \multicolumn{5}{|c|}{ Tectonic elements Cracked surfaces are smoothed by tectonics slides } \\
\hline \multicolumn{2}{|c|}{ Rock mass parameters } & Minimum & Maximum & Average & Standard deviation \\
\hline \multirow{2}{*}{ Physical properties } & Unit weight $-\gamma\left(\mathrm{kN} / \mathrm{m}^{3}\right)$ & 2.1 & 2.4 & 2.25 & 0.24 \\
\hline & Density-w(\%) & 1.83 & 7.36 & 4.6 & 2.8 \\
\hline \multirow{3}{*}{ Mechanical properties } & Uniaxial compressive strength $-q_{u}(\mathrm{MPa})$ & 1.06 & 2.5 & 1.78 & 1.02 \\
\hline & Shear strength $-c_{u}(\mathrm{MPa})$ & 0.53 & 1.6 & 1.06 & 0.37 \\
\hline & Poisson's ratio- $v$ & 0.21 & 0.26 & 0.235 & 0.03 \\
\hline In situ stress & \multicolumn{5}{|c|}{ Overall rock mass strength usually exceeds in situ stress } \\
\hline Water & \multicolumn{5}{|c|}{ Joint water, damp to wet, locally dripping, rarely flowing } \\
\hline
\end{tabular}

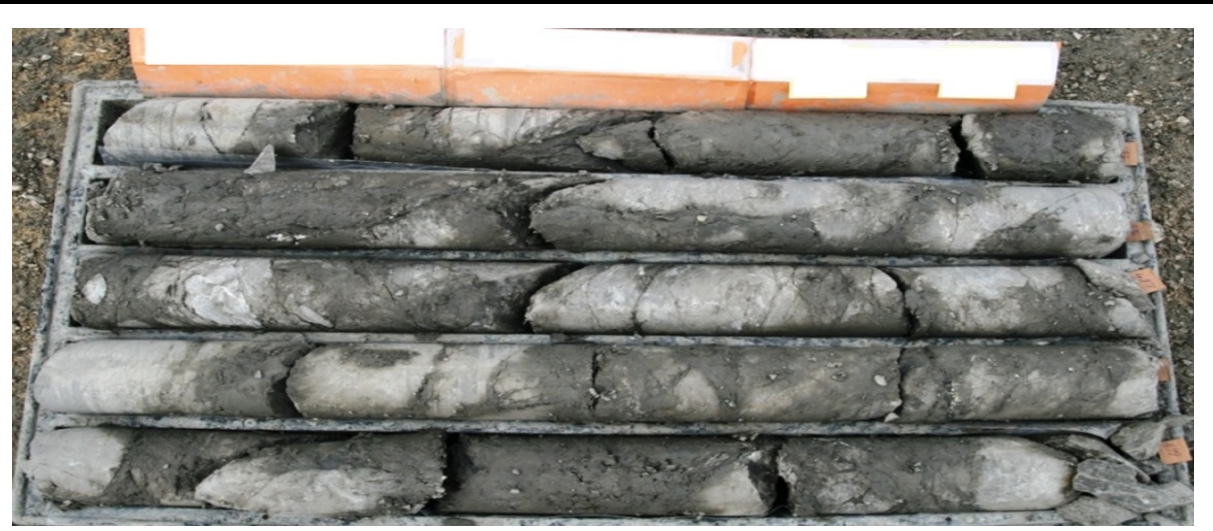

Fig. 1 Core samples from range $494 \mathrm{~m}$ to $499 \mathrm{~m}$.

Table 2 Overview of the computational assessment.

\begin{tabular}{lll}
\hline Jethwa & Singh & Goel \\
\hline$N_{c}=\frac{\sigma_{c m}}{p_{0}}=\frac{\sigma_{c m}}{\gamma H}$ & $H \gg 350 Q^{1 / 3}$ & $H \gg\left(270 N^{1 / 3}\right) B^{0.1}$ \\
$N_{c}=0.16$ & $494 \gg 44.33$ & $494 \gg 39.83$ \\
\hline Highly faulted grounds & Highly faulted grounds & Highly faulted grounds \\
\hline
\end{tabular}

$N_{c}$-rock mass number by Jethwa et al. [9]; $\sigma_{c m}$ —uniaxial compressive strength; $p_{0}$-in situ stress; $\gamma$ —rock mass unit weight;

$H$-depth; $Q$-rock mass quality by Barton et al. [10]; $N$-rock mass number by Goel et al. [1]; $B$ - diameter. 


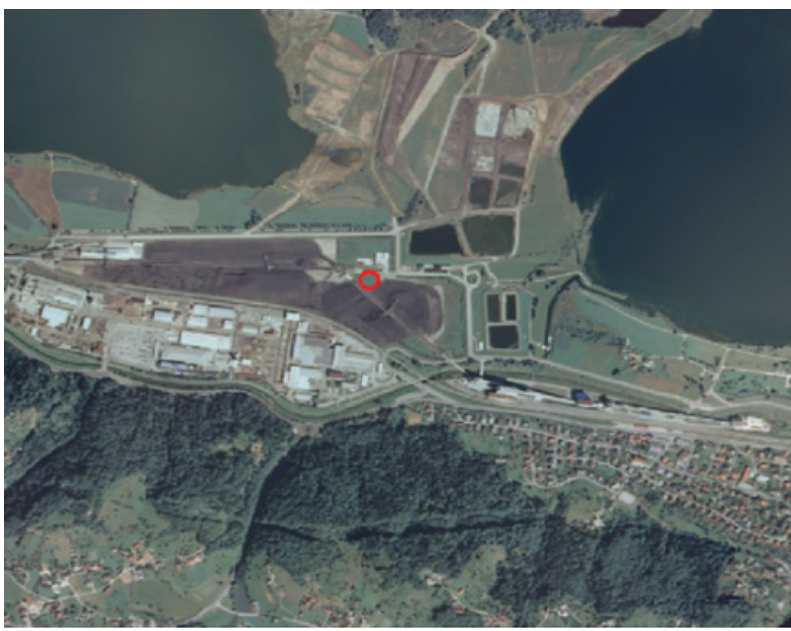

(a)

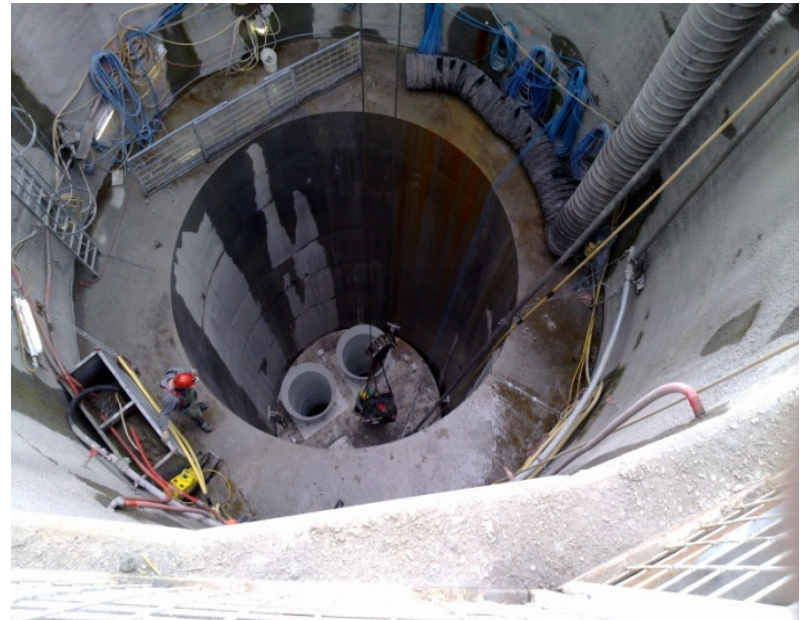

(b)

Fig. 2 (a) The location of the shaft is close to the Velenje Coal Mine in Slovenia; (b) the first and second section during shaft sinking.

\begin{tabular}{|c|c|c|c|c|c|c|c|c|c|c|}
\hline 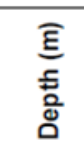 & $\begin{array}{l}\text { 츰 } \\
\text { 응 } \\
\text { ․ㅗㅀ }\end{array}$ & Description & 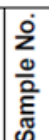 & 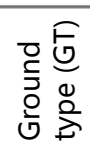 & 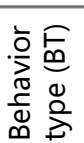 & 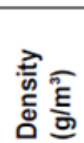 & $\begin{array}{l}\frac{0}{3} \\
\frac{0}{2}\end{array}$ & 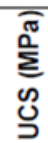 & 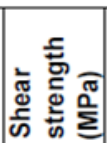 & 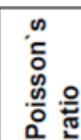 \\
\hline
\end{tabular}

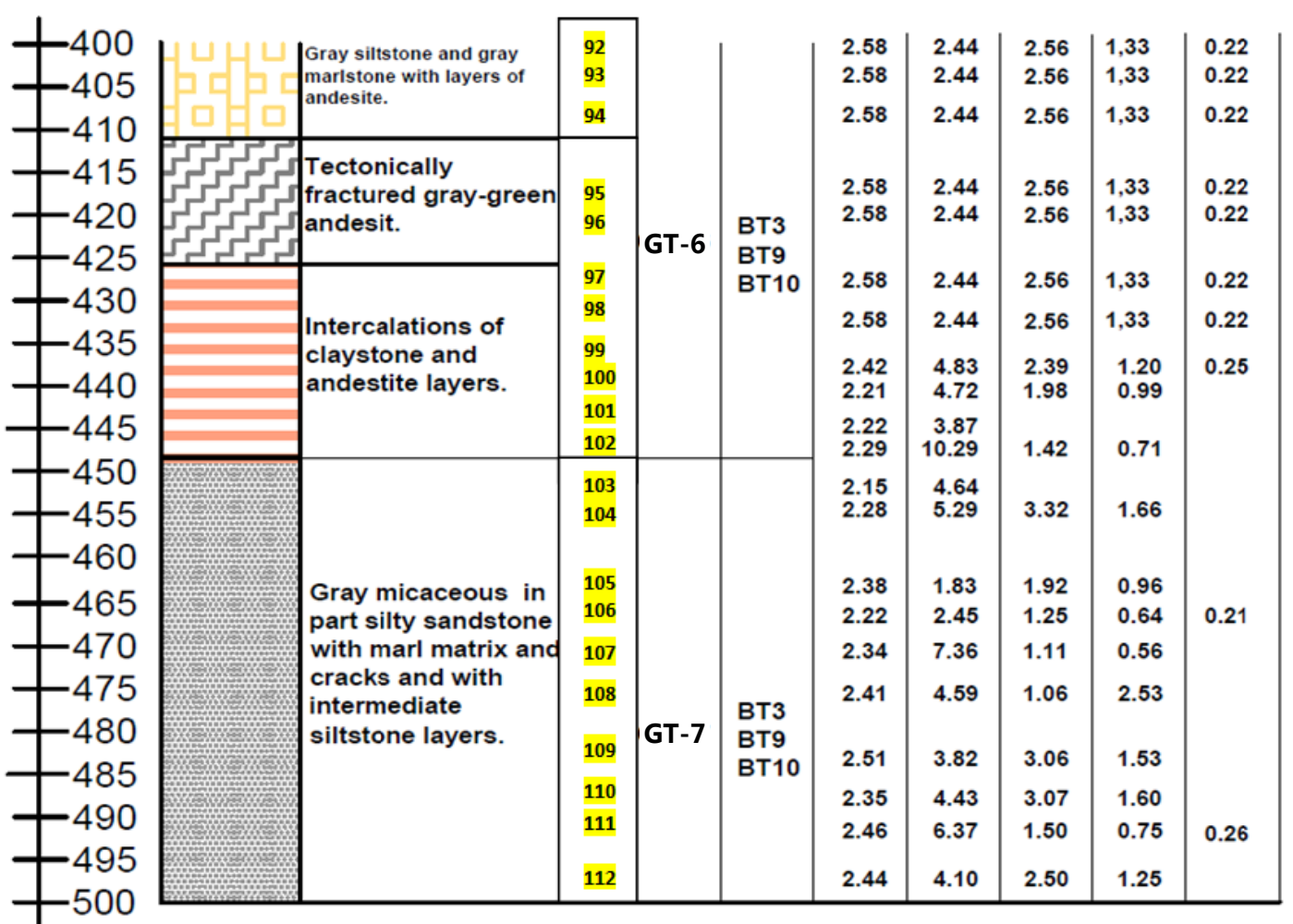

Fig. 3 Lithology with description and geotechnical parameters.

UCS - uniaxial compressive strength.

the shaft excavation profile, which might adversely affect the stability of the surrounding ground layers during the shaft sinking.

For the investigated depth, GTs (ground types) 6 and
7 have been classified and BTs (behavior types) 3, 9 and 10 have been determined (Fig. 3).

Based on the presented GTs above, the primary stress state, shape and size of the underground structure, 
method of excavation and presence of groundwater for the analyzed area and three BTs were established, which were considered in the construction of the basic geotechnical model (Fig. 4).

\section{Mechanical Characteristic of Support Elements}

The modulus of elasticity of hardened shotcrete $\left(E_{b b, s t r}\right)$ generally ranges up to $15,000 \mathrm{MPa}$. For fresh and semi-fresh shotcrete, the modulus of elasticity $\left(E_{b b, s v}\right)$ is equal to 3,000 $\mathrm{MPa}$. In each excavation phase that included an installation of primary lining, modulus of elasticity for the fresh stage of solidification of shotcrete was prescribed. For primary lining which was installed in earlier stages, the elastic modulus $\left(E_{b b, s t r}\right)$ was prescribed.

\subsection{Yielding Elements}

An ordinary shotcrete lining exhibits a high lining resistance but an extremely low deformation capacity [13]. In the case of an overload, shotcrete lining generally loses its load-bearing capacity due to brittle failure even if it is reinforced with customary steel mesh. Therefore, a shotcrete lining without special measures is not suitable for application under highly faulted ground conditions. Nowadays, reliability of primary support systems can be improved by using recently discovered yielding elements that enable controlled release of the primary support system
$[14,15]$. In fact, the yielding elements are able to incorporate defined changes and can, furthermore, plastically deform due to increased loads along the lining circumference.

A part of this extended research is also the development and the production of a unique yielding element. Uniaxial compression test was carried out using an electronically controlled hydraulic press with a capacity of $1,150 \mathrm{kN}$. Vertical displacements and normal force were measured. Yielding element shows strains around $48 \%$ with increasing normal force (Fig. 5).

Total displacements are larger if the yielding elements are installed but final axial force in shotcrete lining is much lower. The integration of yielding elements in shotcrete lining allows a substantially greater failure of rock mass. However, lining must be compatible with the deformability of other support elements. Shotcrete is one of the most commonly used support elements, therefore, a comparison between shotcrete lining with incorporating yielding elements and without the yielding elements is carried out. It is considered that shotcrete thickness is uniform and the shaft is of a circular shape. Geometry profiles of shaft and access tunnel are shown in Fig. 6. Young's modulus is assumed to be constant, while the shotcrete strength is time dependent. We can conclude that a support failure occurs in a lining without the yielding elements, because it is unable to accommodate the

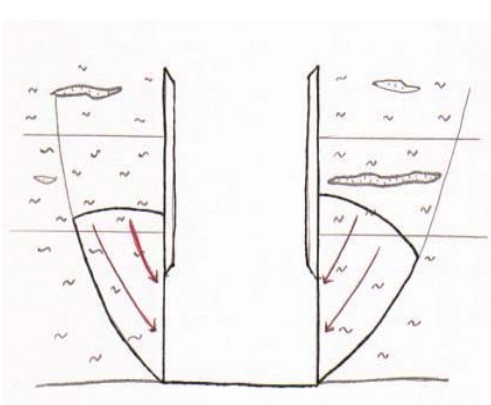

(a)

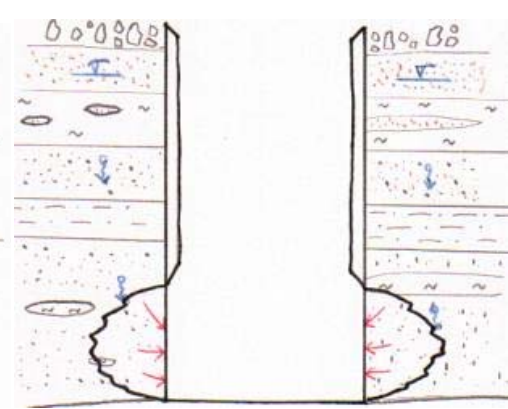

(b)

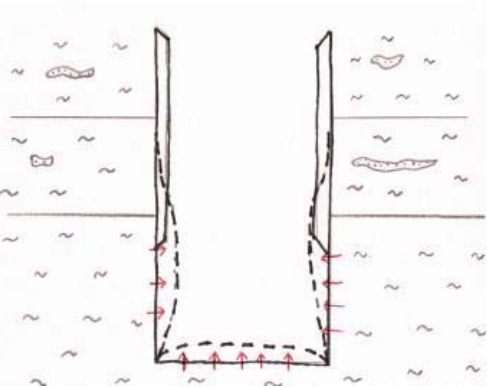

(c)

Fig. 4 Behaviour types: (a) BT3; (b) BT9; (c) BT10.

Table 4 Mechanical characteristics of shotcrete.

\begin{tabular}{llll}
\hline Material & Modulus of elasticity $(\mathrm{MPa})$ & Shotcrete quality & Thickness of primary lining $(\mathrm{cm})$ \\
\hline Primary shaft lining & $3,000-15,000$ & $\mathrm{C} 20 / 25$ & $20-40$ \\
\hline
\end{tabular}




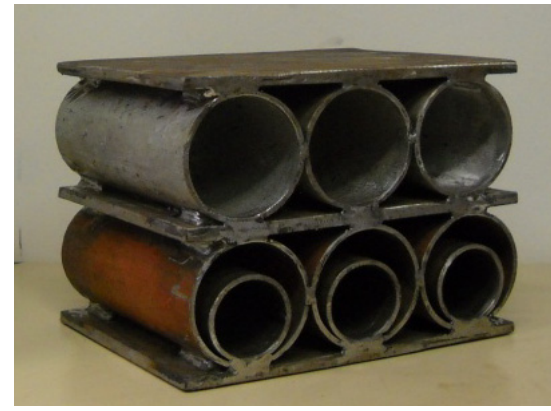

(a)

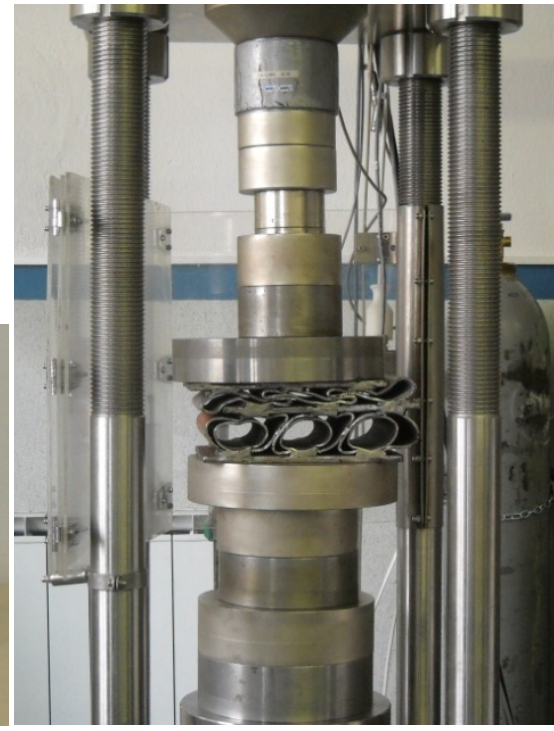

(b)

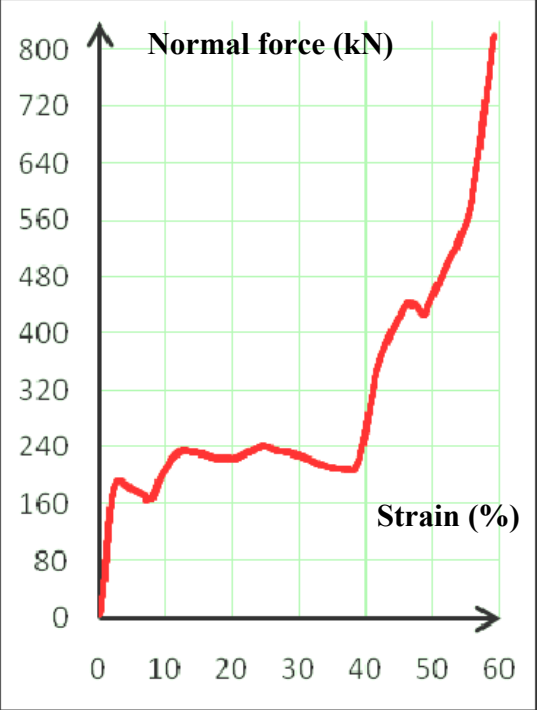

(d)

Fig. 5 (a) The yielding element before the compression; (b) the compression of a yielding element by centric normal force; (c) the yielding element after the compression; (d) normal force: axial strain graph showing a yielding element behavior.

pressure and displacements, generated by excavation works and, consequently, ground mass relaxation. However, the main aim is to achieve a state of equilibrium and it is often necessary to install a support as close as possible to the excavation face to ensure the safety of the workers.

\section{Constitutive Models, Stress Distribution, and Numerical Model}

In the presented geostatic analysis of the permanent mine structures, due to the complexity of the excavation and support definition, the Mohr-Coulomb elastic-plastic material model was found as the most appropriate and effective.

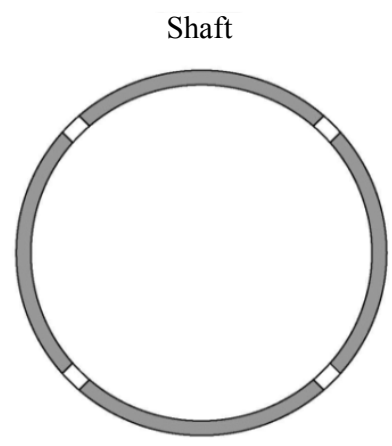

Roadway

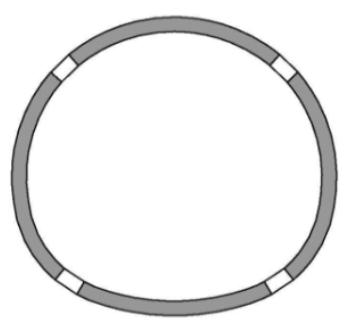

Fig. 6 Geometry profiles of shaft and roadway. 
For the purpose of carrying out the geotechnical analysis, a 3D numerical model (Fig. 7) with the dimensions $(120 \mathrm{~m} \times 100 \mathrm{~m} \times 150 \mathrm{~m})$ was created. In total, 95,000 finite elements were used to form the mesh, in particular, tetrahedron and plain triangular elements. A 3D numerical analysis was performed using the Midas GTS (geotechnical and tunnel system) computer code [16].

All finite elements were interconnected in discretization points. The calculation was based on an iterative method to achieve the desired accuracy of the convergence of displacements (force increment $(\Delta F)$ is less than $0.001 \mathrm{kN})$. The boundary conditions were defined in a way that all boundary joints of finite elements are stationary and restrained perpendicularly to the base plane. However, the other degrees of freedom were unrestrained.

\section{3D Geostatic Numerical Analysis of the}

\section{Connection between Mine Permanent Facilities and Shaft Primary Lining}

In the numerical analysis of the excavation and support measures, undrained conditions with drained shear parameters were included in all the phases. Thus, the principle of effective stresses was used. The most important goal of the analysis was to find out the

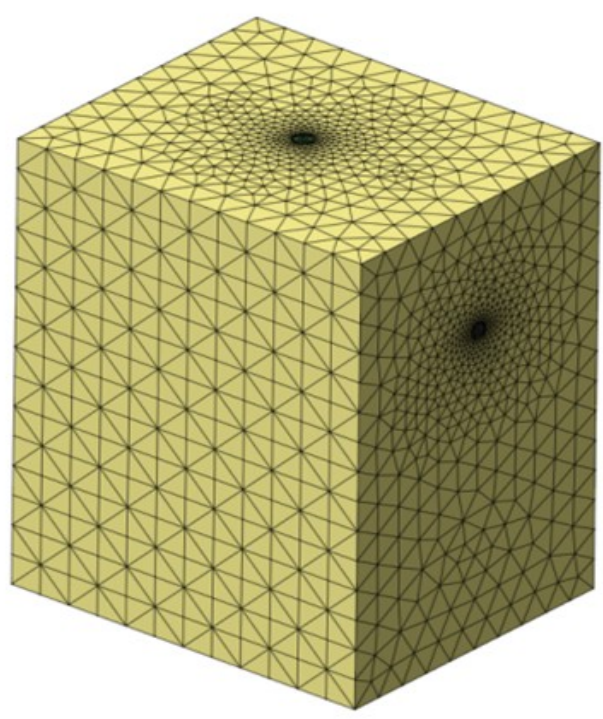

(a) behavior of the implemented yielding support system after the excavation. Therefore, the characteristic values of loads, strength and deformability parameters of the ground were considered. The relation between the vertical and the horizontal primary stress $\left(K_{0}=1\right)$ was taken into account. Analysis was made for the depth of $400-500 \mathrm{~m}$. With the geostatic numerical analysis, the connection between the shaft and the mining track was assessed. The main aim of the analysis was to determine the influence of mine roadways and other connections to the shaft. In all the sections, which simulate the construction of mine facilities that are connected to the shaft, including sinking procedure with primary lining installation, the following numerical simulation procedure was followed:

(1) In the first stage, a primary stress state was determined using undrained ground conditions;

(2) In the second stage, the upper part of the shaft was analyzed to ensure proper stress field at the depth of a particular section;

(3) Furthermore, the permanent mine roadways close to the shaft and shaft sinking were simulated, each step measuring $3 \mathrm{~m}$ in length (depth) with a yielding support system installed with a delay of one step for each excavation phase.

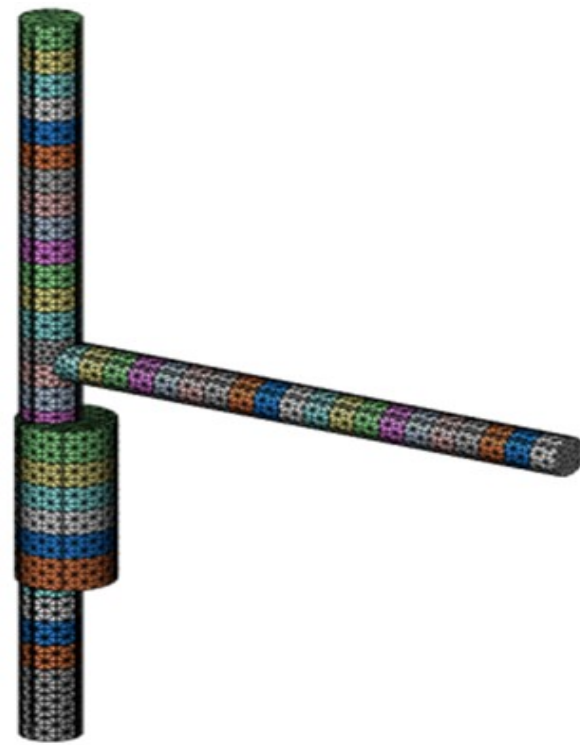

(b)

Fig. 7 3D numerical model. 
The results of the extensive $3 \mathrm{D}$ analysis showed that the connection between permanent mine roadways and shaft lining must be studied and designed very carefully. Furthermore, it was found that it is possible to maintain roadway excavation profiles and a stable shaft with ductile support. The capacity of shotcrete lining is sufficient and the yielding elements deform properly. In Fig. 8, the displacement diagram is shown. The maximum magnitude of the radial displacement in the shaft extension area and in the connection between the shaft and the roadway is approximately $50 \mathrm{~cm}$.

The axial force and yielding stresses in the yielding elements are shown in Fig. 9. The results of the

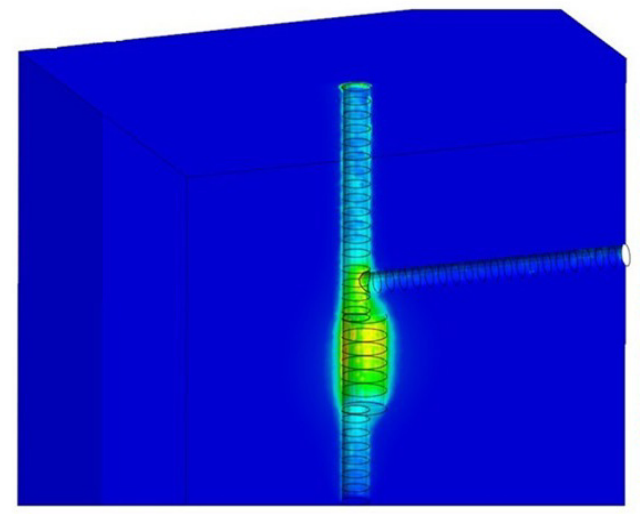

(a)

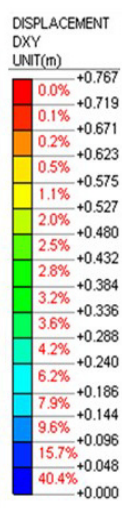

Fig. 8 (a) Horizontal displacements around the shaft; (b) vertical displacements around the roadway and the connection between the shaft and the roadway.

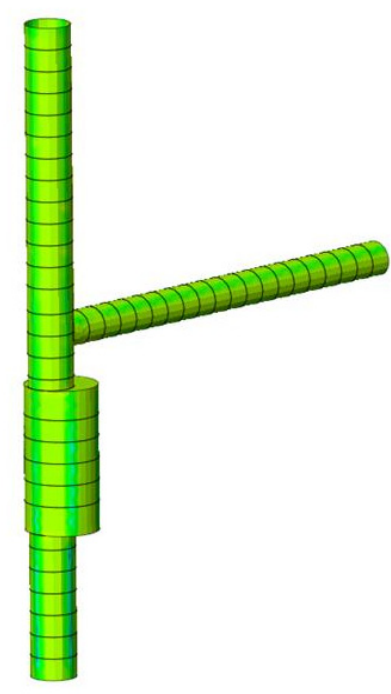

(a)

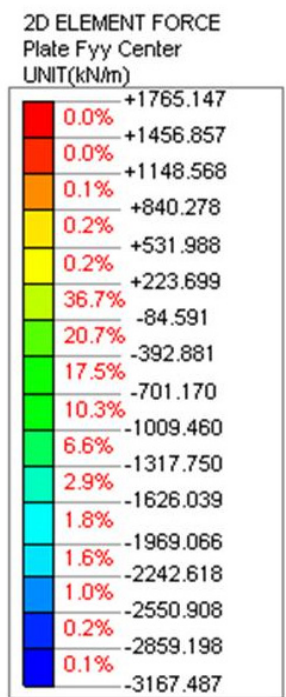

$-3167.487$

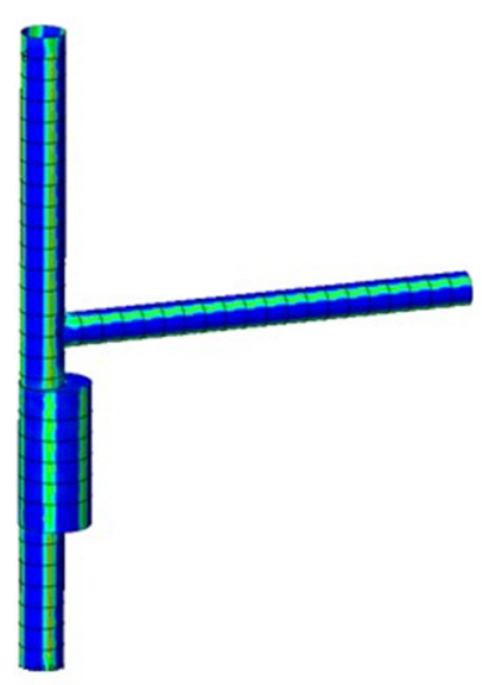

(b)

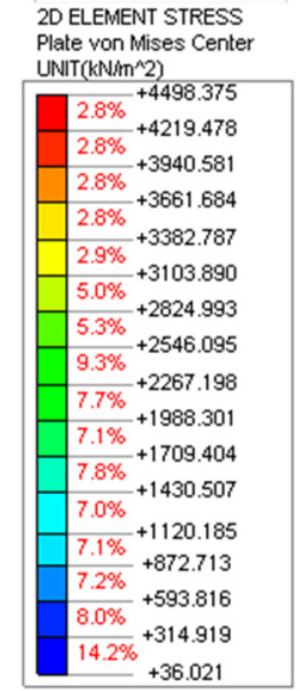

Fig. 9 (a) Axial forces in ductile lining with shotcrete and yielding elements; (b) plasticity occurrence in yielding elements in ductile lining. numerical analysis show that the use of ductile support in highly faulted ground is necessary. In case of a regular support system usage, there would be a very high risk of shotcrete cracking or even of exposing the whole support system to failure.

\section{Additional Analysis of the Shaft Excavation from 400-505 $\mathrm{m}$ in Depth}

The impact of the interaction between the support system and the ground on the geo-metrical and geotechnical conditions of shaft sinking at greater depths was analyzed using equilibrium equations with an explicit solution. They were developed on the basis

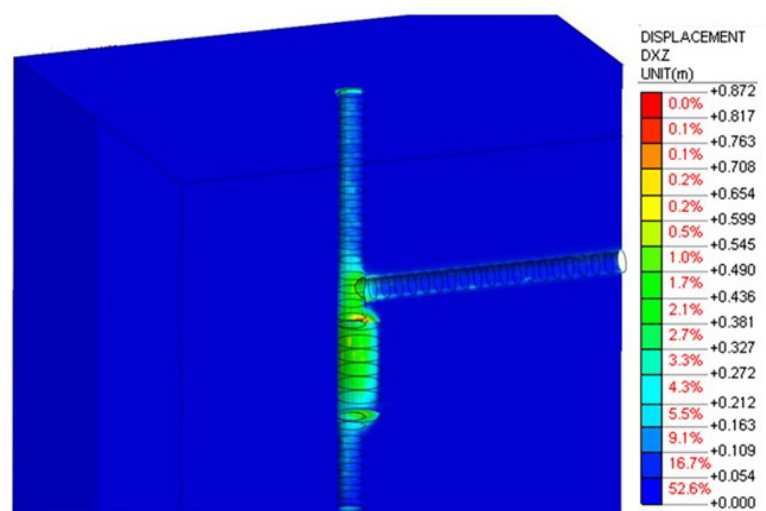

(b)

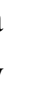




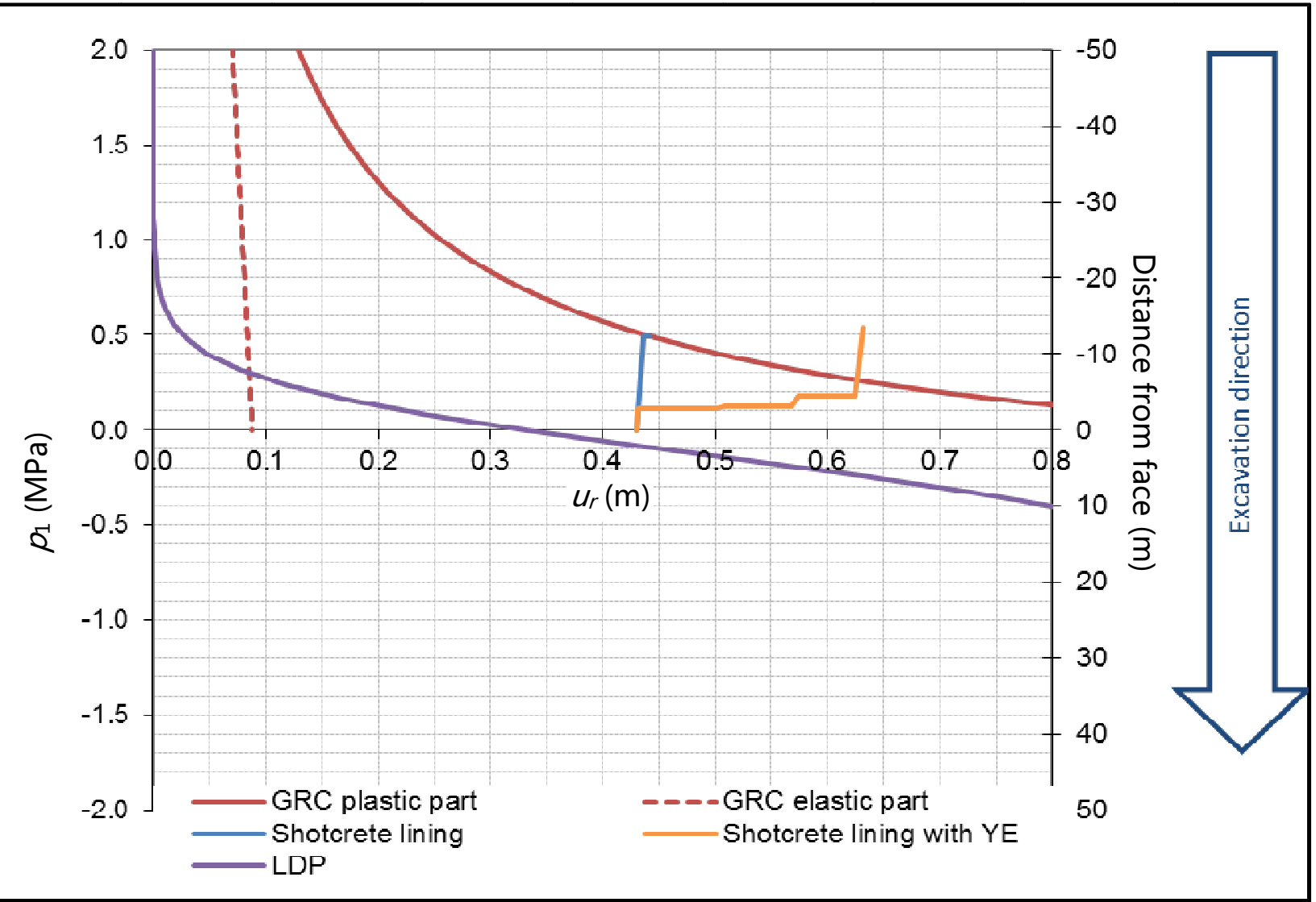

Fig. 10 The differences between the support-ground reaction system with and without the incorporated yielding elements [17].

GRC—-ground reaction curve; LDP—-longitudinal deformation profile; YE—yielding element; $u_{r}$ —radial displacement.

and assumptions of stress and strain changes in homogenous and isotropic grounds. The Duncan-Fama Method was used, based on the Mohr-Coulomb's plastic yield conditions. Furthermore, the default function of the longitudinal deformation profile (Vlachopolous et al. [18]) was implemented. The results of the presented calculated displacements along the longitudinal section have shown that the estimated pre-deformation $\left(u_{\text {pred }}\right)$ below the shaft bottom was approximately $30 \mathrm{~cm}$. In the analysed section, $2 \mathrm{~m}$ above the bottom of shaft, the total radial displacement was formed and extended, approximately $42.5 \mathrm{~cm}$ (Fig. 10).

An appropriate solution would be to install yielding elements, which take into account a bigger deformation tolerance, approximately $40 \mathrm{~cm}$. In the case of a rigid support system, the final total radial displacement is about $40 \mathrm{~cm}$, together with the pre-deformation part.
The plastic radius around the shaft profile, supported by rigid support, is estimated at $13.8 \mathrm{~m}$. In the case of stiff primary lining, the deformation tolerance $\left(t_{d}\right)$ is estimated at $12.5 \mathrm{~cm}$. In comparison to the case where the $20 \mathrm{~cm}$ thick yielding elements in the primary lining are used, the final radial displacement extends by an additional $20 \mathrm{~cm}$.

\section{Conclusions}

Identification of the rate of faulted grounds could be calculated with high precision using theories by authors mentioned above and could be obtained from available geotechnical data during further investigation. The 3D numerical geo-mechanical model, based on case history of the presented data, provides a solution in yielding support measures. Additional geotechnical measurements and geological observations, which will be a part of the technological construction procedure, 
will present a great opportunity to find a proper solution for overcoming inevitable problems. The yielding elements should be compatible with shotcrete lining, the stress and strain effects of yielding and ground properties could be evaluated with ground reaction curve, longitudinal displacement profile and support characteristic curve.

\section{Acknowledgments}

The authors sincerely acknowledge Innovative Scheme for Co-Financing of Doctoral Studies.

\section{References}

[1] R. Goel, J. Jethwa, G. Paithankar, Tunnelling through the young Himalayas - A case history of Maneri-Uttarkashi power tunnel, Engineering Geology 39 (1995) 31-44.

[2] R.K. Goel, J.L. Jethwa, B.B. Dhar, Effect of tunnel size on support pressure, International Journal of Rock Mechanics and Mining Sciences 33 (7) (1996) 749-755.

[3] B. Singh, J.L. Jethwa, A.K. Dube, B. Singh, Correlation between observed support pressure and rock mass quality, Tunnelling and Underground Space Technology 7 (1992) 59-74.

[4] M. Singh, B. Singh, J. Choudhari, Critical strain and squeezing of rock mass in tunnels, Tunnelling and Underground Space Technology 22 (2007) 343-350.

[5] O. Aydan, T. Akagi, T. Kawamoto, The squeezing potential of rocks around tunnels: Theory and prediction, Rock Mechanics and Rock Engineering 26 (2) (1993) 137-163.

[6] E. Hoek, Big tunnels in bad rock, Journal of Geotechnical and Geoenvironmental Engineering 127 (2001) 726-740.

[7] E. Hoek, R. Guevara, Overcoming squeezing in the Yacambú-Quibor tunnel, Venezuela, Rock Mechanics and Rock Engineering 42 (2009) 389-418.
[8] E. Hoek, P. Marinos, Predicting tunnel squeezing problems in weak heterogeneous rock masses, Tunnels and Tunnelling International 45-51 (part I) and 33-36 (part II), 2000.

[9] J.L. Jethwa, B. Singh, B. Singh, Estimation of ultimate rock pressure for tunnel linings under squeezing rock coditions-A new approach, in: E.T. Brown, J.A. Hudson, J.A. (Eds.), Proccedings of International Society for Rock Mechanics Symposium on Design and Performance of Underground Excavations, Cambridge, 1984, pp. 231-238.

[10] N. Barton, R. Lien, I. Lunde, Engineering classification of rock masses for the design of tunnel supports, Rock Mechanics 6 (4) (1974) 189-239.

[11] O. Aydan, T. Akagi, T. Kawamoto, The squeezing potential of rock around tunnels: Theory and prediction with examples taken from Japan, Rock Mechanics and Rock Engineering 29 (1996) 125-143.

[12] G. Barla, Squeezing rocks in tunnels, International Society for Rock Mechanics News J. 2 (3/4) (1995) 44-49.

[13] G. Barla, M. Bonini, M. Semeraro, Analysis of the behaviour of a yield-control support system in squeezing rock, Tunnelling and Underground Space Technology 26 (2011) 146-154.

[14] K. Opolony, Status of the roadway support system in RAG German coalmine, Glückauf 3 (2011) 79-85.

[15] K. Opolony, H.B. Einck, M. Thewes, Testing of yielding elements for ductile support, presented in: ITA-AITES World Tunnel Congress and 37th General Assembly, Helsinki, 2011,.

[16] Basic \& Advanced Tutorials, MIDAS IT Co., Ltd., Beijing, 2002.

[17] T. Marolt, Construction of underground structures in high squeezing grounds, B.Sc. thesis, University of Ljubljana, 2011.

[18] N. Vlachopoulos, M.S. Diederichs, Improved longitudinal displacement profiles for convergence confinement analysis of deep tunnel, Rock Mechanics and Rock Engineering 42 (2009) 131-146. 